\title{
Emergence of Midges (Chironomidae, Diptera) \\ from a Saline Lake as a Source of Organic Matter and Essential Biochemical Compounds for Arid Ecosystems in South Siberia
}

\author{
Elena V. Borisova ${ }^{a}$, Alexander P. Tolomeev ${ }^{b}$, \\ Anton V. Drobotov ${ }^{\mathrm{b}}$ and Nadezhda N. Sushchik ${ }^{* a, b}$ \\ ${ }^{a}$ Siberian Federal University \\ 79 Svobodny, Krasnoyarsk, 660041, Russia \\ ${ }^{b}$ Institute of Biophysics SB RAS \\ $F R C$ "Krasnoyarsk Science Center SB RAS" \\ 50/50 Akademgorodok, Krasnoyarsk, 660036, Russia
}

Received 17.10.2017, received in revised form 15.11.2017, accepted 16.11.2017

Midges (Chironomidae, Diptera) are dominant amphibiotic insects in zoobenthos of the large saline Lake Shira located in the arid landscape of South Siberia. During two vegetation seasons we measured the dynamics of chironomid emergence from littoral parts of four stations in the lake. During one of the vegetation seasons we also measured chironomid emergence from profundal parts (depth of $6 \mathrm{~m}$ ) of the same stations using original floating traps. Both seasonal dynamics and daily means of emergence values significantly varied among the studied stations and depths and were related to the bottom sediment type. The annual export of wet biomass (calculated as the sum of daily values for a vegetation season) was equal to $0.61 \mathrm{~g}$ per square meter of water surface and included proportional contributions of the areas with various bottom sediment types. Based on the values of benthic secondary production, we estimated additional annual export of chironomid biomass from the profundal part of the lake of approximately $1 \mathrm{~g}$ of wet weight $\cdot \mathrm{m}^{-2}$. Besides, the total export of polyunsaturated fatty acids (PUFA) calculated using the previous data on PUFA content in the studied chironomid taxa $\left(\sim 2 \mathrm{mg} \cdot \mathrm{m}^{-2}\right.$ year $\left.{ }^{-1}\right)$ appeared to be one of the lowest when compared to estimations for chironomids and some other amphibiotic taxa from similar steppe landscapes.

Keywords: amphibiotic insects, Chironomidae, emergence, saline lake, arid landscape.

Citation: Borisova E.V., Tolomeev A.P., Drobotov A.V., Sushchik N.N. Emergence of midges (Chironomidae, Diptera) from a saline lake as a source of organic matter and essential biochemical compounds for arid ecosystems in South Siberia. J. Sib. Fed. Univ. Biol., 2019, 12(2), 196-215. DOI: 10.17516/1997-1389-0293.

(C) Siberian Federal University. All rights reserved

This work is licensed under a Creative Commons Attribution-NonCommercial 4.0 International License (CC BY-NC 4.0).

* Corresponding author E-mail address: labehe@ibp.ru 


\title{
Вылет хирономид (Chironomidae, Diptera) из соленого озера как источник органического углерода \\ и незаменимых биохимических веществ для аридных экосистем юга Сибири
}

\author{
Е.В. Борисова ${ }^{\text {a }, ~ А . П . ~ Т о л о м е е в ~}{ }^{\sigma}$, \\ А.В. Дроботов ${ }^{\tilde{0}}$ Н.Н. Сущик ${ }^{\mathrm{a}, \boldsymbol{\sigma}}$ \\ ${ }^{a}$ Сибирский федеральный университет \\ Россия, 660041, Красноярск, пр. Свободный, 79 \\ ${ }^{6}$ Институт биофизики СО РАН \\ ФИЦ «Красноярский научныий иентр СО РАН» \\ Россия, 660036, Красноярск, Академгородок, 50/50
}

Комары-звонщы (сем. Chironomidae, Diptera) являются доминирующими амфибионтными насекомыми в составе зообентоса крупного соленого оз. Шира, расположенного в степном аридномландиафте Южной Сибири. В течениедвухвегетационныхсезонов измеряли динамику и интенсивность вылета имаго хирономид на литорали четырех станиий данного водоема. В течение одного вегетационного сезона дополнительно измеряли интенсивность вылета хирономид с глубоководных (6 метров) участков тех же станиий с помощью имагоуловителя плавающей оригинальной конструкции. Сезонная динамика и среднесуточная интенсивность вылета значительно варьировали между станциями и глубинами, в зависимости от типа грунтов. Величина годового вылета имаго (суммы за вегетационный сезон) составила 0.61 г сырой массы $\cdot \cdot^{-2}$ акватории озера, пригодной к выплоду хирономид, с учетом вкладов площади грунтов всех типов. Сравнение с величинами вторичной продукции бентоса позволило учесть дополнительный экспорт биомассы за счет вылета хирономид с глубоководных участков озера, который составил около 1 г сырой массы $\cdot M^{-2}$ год-1. Вместе с тем, итоговый экспорт незаменимых полиненасыщенных жирных кислот (ПНЖК), рассчитанный с применением данных о количественном содержании ПНЖК в биомассе изученных таксонов $\left(\sim 2 \mathrm{Mz} \cdot \mathrm{M}^{-2}\right.$ год $\left.{ }^{-1}\right)$, был одним из самых низких по сравнению с измерениями для хирономид и иных групп амфибионтных насекомых, вылетающих из водоемов подобных степных ландшафтов.

Ключевые слова: амфибионтные насекомые, Chironomidaе, вылет, соленое озеро, аридный ландмафт.

\section{Введение}

Согласно современным экологическим представлениям перенос органических веществ и биогенных элементов через границу вода/суша является важнейшим процессом взаимодействия между водными и наземны- ми экосистемами в различных ландшафтах и биомах (Richardson et al., 2010; Schindler, Smits, 2017). Дополнительные источники вещества и энергии, произведенные во внутренних водах, особенно важны в наземных малопродуктивных ландшафтах, например в 
аридных системах пустынь и степей (Gratton, Vander Zanden, 2009; Millan et al., 2011).

Bce потоки органического углерода из воды на сушу возникают в результате деятельности биоты; при этом ключевой из таких потоков обусловлен вылетом амфибионтных насекомых (Baxter et al., 2005; Ballinger, Lake, 2006; Gratton, Vander Zanden, 2009). Даже в сравнительно продуктивных степных и лесных экосистемах продукция, выносимая на сушу амфибионтными насекомыми, может играть значительную роль для наземных консументов. Например, в прериях суточная биомасса вылетающих из ручьев насекомых может в три раза превышать продукцию наземных членистоногих (Gray, 1989), а доля биомассы амфибионтных насекомых из ручьев составляет более 25 \% годового рациона лесной орнитофауны (Nakano, Murakami, 2001). Отмечено, что в прибрежной полосе зачастую питаются такие наземные консументы, как пауки и насекомые (Nakano, Murakami, 2001; Sabo, Power, 2002; Reimer et al., 2010; Stenroth et al., 2015).

Продукция водных экосистем важна для наземных консументов не только с количественной, но и с качественной точки зрения. Известно, что в водных экосистемах отдельные таксоны микроводорослей эффективно синтезируют длинноцепочечные полиненасыщенные жирные кислоты (ПНЖК) семейства омега-3, а именно эйкозапентаеновую кислоту (ЭПК, 20:5n-3) и докозагексаеновую кислоту (ДГК, 22:6n-3), далее мигрирующие по трофическим сетям. Эти вещества присутствуют и у подавляющего большинства всеядных водных и наземных животных, поскольку входят в состав клеточных мембран и регулируют важнейшие физиологические процессы, являясь предшественниками медиаторных соединений (Lands, 2009; Arts, Kohler, 2009). Продуценты суши (высшие и низшие растения, грибы), а также сами всеядные животные, обитающие на суше, не способны синтезировать омега-3 ПНЖК в количествах, необходимых для обеспечения физиологических потребностей последних. Поэтому водная продукция, в том числе биомасса вылетающих амфибионтных насекомых, служит основным источником поступления ЭПК и ДГК в организмы всеядных и хищных обитателей наземных экосистем (Gladyshev et al., 2009, 2013; Hixson et al., 2015).

Таким образом, наряду с потоком общего органического углерода амфибионтные насекомые, включенные на личиночных стадиях в водные трофические сети, выносят на сушу незаменимые ПНЖК. Выполненная ранее глобальная оценка показала, что вылет имаго амфибионтных насекомых из внутренних водоемов на сушу является одним из основных потоков экспорта этих незаменимых веществ из воды на сушу (Gladyshev et al., 2009). Очевидно, что глобальное исследование не учитывало существенной вариабельности потоков органических веществ на сушу разных ландшафтов (биомов), и должно дополняться и проверяться исследованиями отдельных специфичных экосистем.

Центральная и Южная Сибирь отличаются богатством ландшафтов. Значительную площадь данного региона занимают суббореальные континентальные межгорные и предгорные равнины, среди которых на юге распространены типично-степные ландшафты (Ландшафтная карта СССР, 1980), характеризующиеся сравнительно низкой увлажненностью и высокой инсоляцией. Такие физикогеографические условия способствуют формированию значительного числа бессточных озер и рек, имеющих повышенный уровень минерализации. Данный тип экосистем 
имеет достаточно широкое географическое распространение на большинстве континентов (Williams, 1998; Valero-Garces et al., 2000; Marengo et al., 2009; Jeppesen et al., 2015). Однако если в литературе имеются количественные оценки экспорта веществ из пресных водоемов степного ландшафта (Gladyshev et al., 2011), то потоки органического вещества и ПНЖК из соленых водоемов ранее не исследовались. Тем не менее, мы предполагаем, что именно такие типы водоемов оказывают наибольшее влияние на окружающие наземные системы аридных ландшафтов. Состав солей и уровень минерализации, как правило, специфичен, что приводит к редуцированию трофической сети и уменьшению количества видов гидробионтов, способных выживать во внутренних соленых водоемах (Cognetti, Maltagliati, 2000; Herbst, 2001). В зообентосе присутствует относительно малое число видов амфибионтных насекомых, обеспечивающих при этом высокий уровень биомассы и продукции благодаря отсутствию пищевой конкуренции и прямых хищников (например, Толомеев и др., 2018). Следовательно, вылет насекомых из таких водоемов может обеспечивать высокий уровень поступления органического углерода и сопутствующих ПНЖК в наземную часть аридных ландшафтов (Millan et al., 2011).

Таким образом, целью данной работы было определение экспорта биомассы и незаменимых ЭПК и ДГК на сушу за счет вылета амфибионтных насекомых, а именно комаровзвонцов сем. Chironomidae, из соленого озера Шира, расположенного в степном ландшафте юга Сибири (Хакасия).

\section{Район работ, материалы и методы}

Район исследований

Озеро Шира является солоноватым меромиктическим водоемом с площадью водного зеркала около 36 км², максимальной глубиной до 24 м и средними глубинами 10-12 м. Минерализация колеблется в пределах 14-18 г/л, состав воды: сульфатно-хлоридно-натриевомагниевый (Degermendzhy et al., 2010). В безледный период (май-ноябрь) наблюдается ярко выраженная температурная стратификация водной толщи. Характеристики водоема и прилегающих наземных экосистем подробно описаны в предыдущих работах (Природный комплекс..., 2011; Толомеев и др., 2018; Rogozin et al., 2017).

В соответствии с различными типами берегов и грунтов в пределах акватории озера было выделено 4 станции (рис. 1). Грунты на литорали (глубина 1 м) и профундали (глубина 6 м) станции 1 сформированы глинисто-иловыми отложениями; литораль и профундаль станции 2 составлены песчаными грунтами, грунты мелководья и глубоководья станции 3 образованы черными илами, а на литорали также дерниной, литораль станции 4 состоит из дернины, а глубоководная ее часть - из каменисто-обломочных пород и глины (рис. 1). В июне 2017 г. провели картирование грунтов озера, в результате чего уточнили границы распространения четырех основных типов: глинистые илы, песок, каменисто-обломочные породы, дернина (рис. 1). Картирование выполняли путем изымания и визуального осмотра проб грунта каждые 300-500 метров по всему периметру озера на глубине 6 метров, а также в отдельных участках на глубине 2-3 метра с привязкой к географическим координатам с помощью GPS.

Площадь, занимаемая каждым типом грунтов, пригодная для выплода хирономид (т.е. до глубины 7.5 м), была затем рассчитана с помощью программы ImageJ 1.46 на основе спутникового изображения озера (Google Earth, https://www.google.ru/maps). 


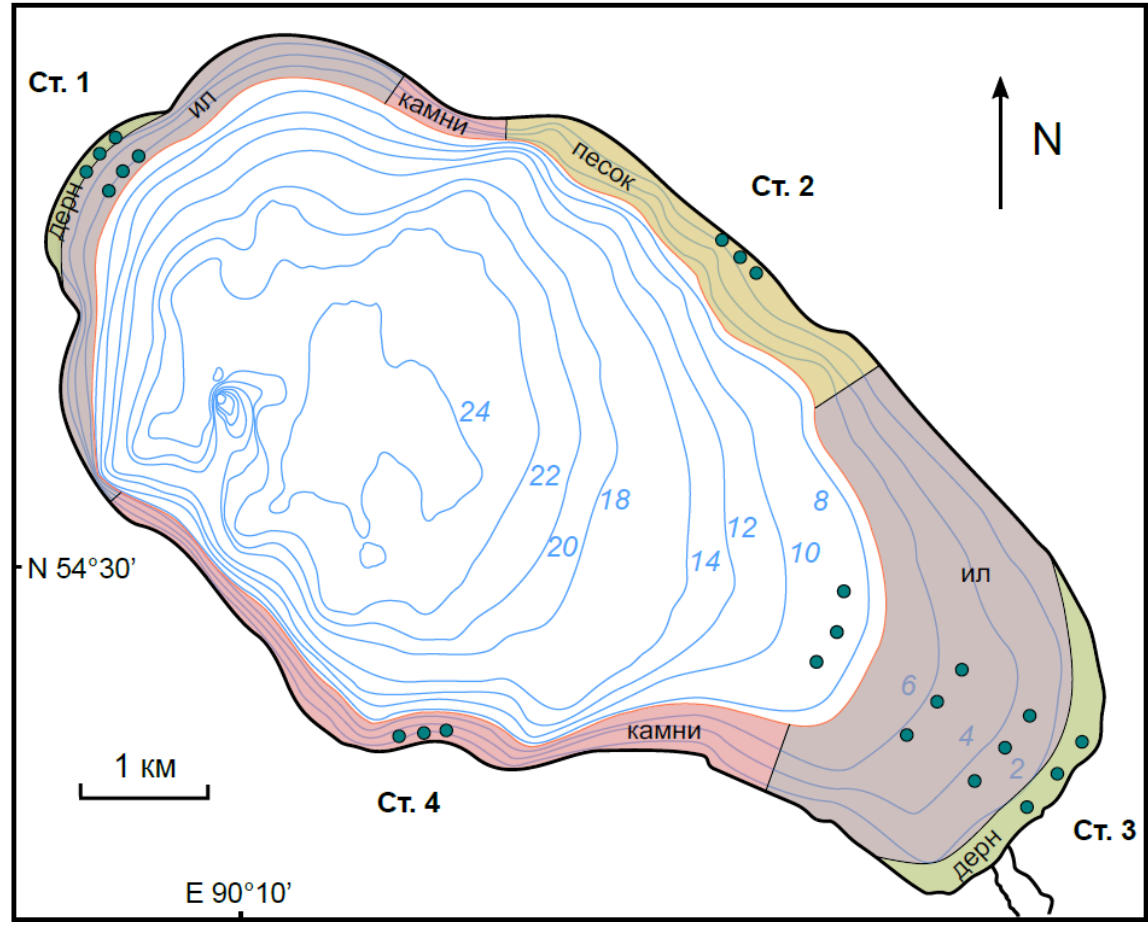

Рис. 1. Схема озера Шира со станциями установки ловушек. Места установки полупогруженных (только 1 м) и плавающих $(1,3,6,9$ м) ловушек обозначены кружками. Окрашенная часть акватории - площадь, пригодная к выплоду хирономид. Цветной заливкой обозначены участки этой акватории с донными грунтами разных типов, границы которых были уточнены при картировании дна

Fig. 1. Map-scheme of Lake Shira with the stations where insect traps were set. The locations of submerged (station depth of $1 \mathrm{~m}$ ) and floating (station depths of 1, 3,6 and $9 \mathrm{~m}$ ) traps are marked with circles. The coloured parts correspond to areas of the lake suitable for chironomid larvae habitats. Each color corresponds to a specific sediment type outlined according to our mapping of the bottom

\section{Сбор проб}

Оценку выплода хирономид проводили путем сбора имаго в конусообразные сетчатые ловушки различных конструкций. В 2016 г. использовали полупогруженные ловушки (Rosenberg et al., 1980; Borisova et al., 2016) с модифицированным съемным сборникомнакопителем для выплодившихся имаго. Нижняя часть конуса ловушки была погружена в воду и удерживалась над дном с помощью эластичных строп, растянутых тремя грузами. Верхняя часть конуса находилась на поверхности благодаря кольцеобразному поплавку, к которому сверху крепился сборникнакопитель. Площадь подводного конуса ловушки составляла $0.28 \mathrm{~m}^{2}$, высота -0.5 м.
Однако такие ловушки можно было использовать только на мелководье, и их конструкция весьма неустойчива в условиях сильных волнений, регулярно происходящих на крупной акватории в степной зоне. Поэтому в 2017 г. были разработаны и использованы плавающие ловушки оригинальной конструкции (рис. 2).

Конус такой ловушки (площадь - 0.64 м², высота -0.6 м) изготавливали из жесткого пластика и внутренней мягкой сетки с окнамипрорезями для ручных манипуляций по установке и снятиию сборника-накопителя (рис. 2). Каркас крепили на обруч-поплавок, удерживаемый на поверхности воды с помощью одиночной капроновой веревки необхо- 


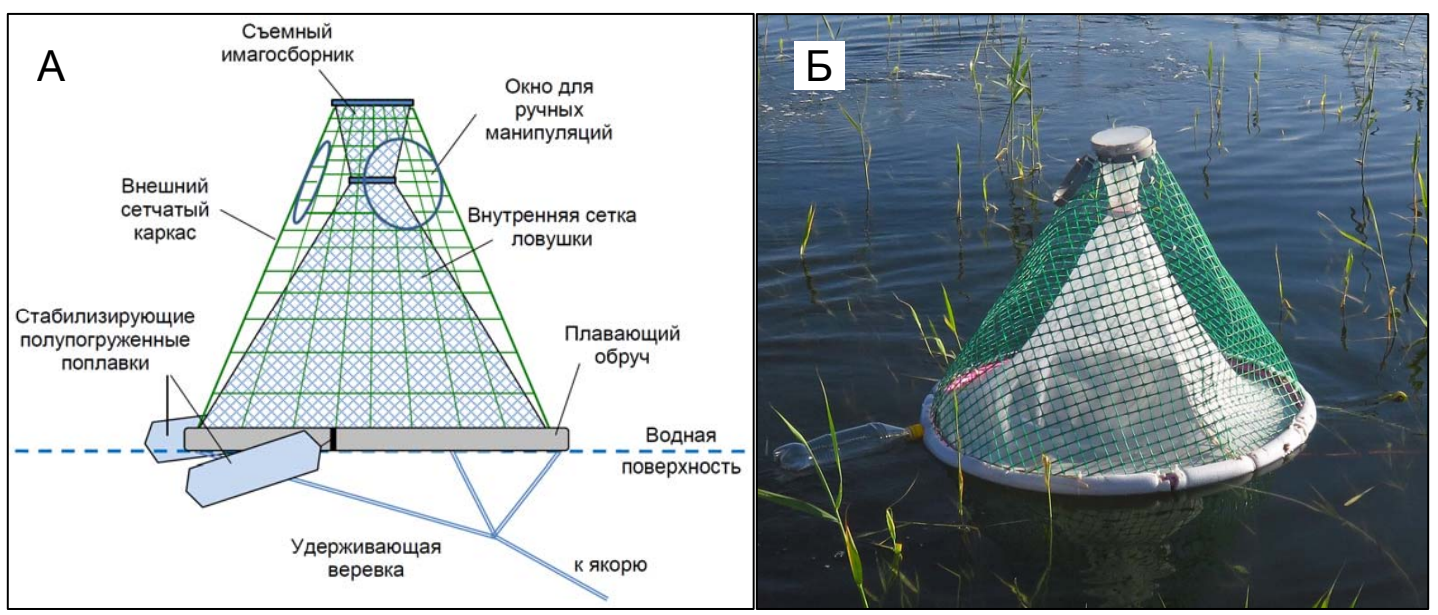

Рис. 2. Плавающая ловушка оригинальной конструкции: схема (А); экземпляр, экспонированный на глубине 1 м, оз. Шира (Б)

Fig. 2. The floating trap: diagram (A); trap exposed at Lake Shira site of $1 \mathrm{~m}$ depth (Б)

димой длины и груза. В верхней части конуса находился съемный сборник-накопитель для выплодившихся имаго. Новая конструкция имела несколько преимуществ по сравнению с ранее используемыми полупогруженными ловушками. Прежде всего, плавающие ловушки могли быть использованы на глубоководных участках озера. Во-вторых, конструкция не имела подводной части, что позволяло избежать привлечения к ней особей бокоплавов Gammarus lacustris, обладающих развитым тигмотактическим поведением (Starry et al., 1998). Известно, что бокоплавы способны сосредотачиваться в большом количестве под конусами полупогруженных ловушек, снижая тем самым вероятность благополучной миграции куколок хирономид к собирающей емкости и последующего превращения в имаго.

В 2016 г. было установлено по три полупогруженных ловушки на литорали (глубина до 1 м) четырех станций (рис. 1). Учеты выплода имаго хирономид проводили с первой декады июня до второй декады августа за несколько периодов длительностью по 5-14 дней.
В 2017 г. использовали плавающие ловушки, и на литорали четырех станций было также установлено по три их экземпляра. Кроме того, было размещено по три плавающих ловушки над 6-метровыми глубинами станций 1 и 3, и по три ловушки над 3- и 9-метровыми глубинами станции 3 (рис. 1). Учеты выплода имаго хирономид в 2017 г. проводили со второй декады мая по вторую декаду сентября в несколько этапов длительностью по 5-14 дней. Общее время постановки ловушек составило 48 и 78 дней в 2016 и 2017 гг., соответственно.

Окрылившихся имаго из ловушек изымали раз в двое суток. При отборе проб съемный сборник заменяли на новый, а изъятие особей хирономид производили в лабораторных условиях. Рассчитывали средние значения количества вылетевших имаго для ловушек, установленных на данной станции, на данной глубине.

Собранных особей сортировали по нескольким морфологически близким группам (видам либо родам), учитывающим размер, пол и визуально различимые таксономические признаки, подсчитывали и взвешивали. 
Взвешивание проводили на аналитических весах HR-150AZ (A\&D, Корея) с дискретностью определения массы до 0.1 мг. Полученные средние значения сырой массы особи для каждой морфологической группы затем использовали для расчета вклада группы в общую биомассу в пробе. Всех особей консервировали в 80 \% этаноле для установления видовой принадлежности. Кроме того, определяли влажность отдельно собранных на побережье проб имаго доминирующих таксонов для пересчета биохимических показателей на единицу сухой массы.

Видовую принадлежность массовых видов комаров-звонцов устанавливали по препаратам гениталий самцов (Определитель насекомых Дальнего Востока России, 1999; Langton, Pinder, 2007; Contreras-Lichtenberg, 1999). Таксономическое определение уточняли у сотрудников лаборатории пресноводной гидробиологии ФНЦ Биоразнообразия ДВО РАН Е.А. Макарченко и О.В. Орел.

\section{Расчеты суточного и годового вылета на единицу площади акватории}

Для каждой даты учетов на основании биомассы хирономид, попавшихся в ловушки, были рассчитаны суточные значения вылета $\left(г \cdot \mathrm{M}^{-2} \cdot\right.$ сут $\left.^{-1}\right)$. Среднесуточный вылет с единицы водной площади, пригодной для выплода, был рассчитан как среднеарифметическое значение измерений за все даты в период проведения учетов двух (или одного) вегетационных сезонов на данной станции и глубине.

При расчетах годового вылета насекомых принимались во внимание следующие факторы: а) межсезонное и внутрисезонное варьирование интенсивности вылета; б) наличие одного или двух пиков вылета; в) сдвиг начала и длительности вылета в зависимости от погодных условий (Lundstrom et al., 2010). В экосистемах умеренного климата ключе- вым фактором, определяющим начало массового выплода амфибионтных насекомых, является сезонный подъем температуры воды (Fureder et al., 2005), в значительной степени связанный с подъемом температуры воздуха (Livingstone, Lotter, 1998).

В связи с неполнотой имевшихся рядов температуры воды, мы использовали данные температуры воздуха как прокси-показатель динамики температуры воды. Среднесуточные измерения температуры воздуха были получены с помощью погодной станции Vantage Pro 2 6152CEU (Davis Instruments, США), установленной на территории научного стационара ИБФ СО РАН в непосредственной близости от озера, а также предоставлены отделом Росгидрометеослужбы для стационарного поста наблюдений, расположенного в 10 км от озера. Для определения сезонной динамики вылета хирономид с учетом измерений разных вегетационных сезонов была использована модель, где в качестве показателя времени вегетационного сезона применили сумму положительных температур воздуха от начала сезона (см. Borisova et al., 2016). Для расчетов использованы ряды температур воздуха, в которых суммировали положительные значения. Таким образом, для каждой даты учетов вылета хирономид было получено соответствующее значение суммы положительных температур.

По наблюдениям в 2016-2017 гг. вылет хирономид происходил в интервале от 400 до $2200{ }^{\circ} \mathrm{C}$ суммарных положительных температур, его длительность составила 112 суток. Этот период приняли в расчетах как продолжительность выплода хирономид в течение года. Значения суточного вылета разных дат и годов ранжировали по показателям температур отдельно для каждой станции и глубины. В итоге, для каждой из них был получен модельный сезонный ряд интенсивности вылета 
хирономид разных таксономических групп в зависимости от суммы положительных температур на данные сутки. Для дат, соответствующих показателям суммы температур, когда учеты не проводились, величины вылета были рассчитаны как средние близлежащих значений.

Для каждой станции и глубины рассчитали годовой вылет (г сырой массы · $\mathrm{M}^{-2}$ акватории) как сумму всех значений суточного вылета за модельный период (112 суток). Годовой вынос биомассы за счет вылета хирономид был рассчитан как произведение вылета с какого-либо типа грунта на площадь данного типа, затем вылет хирономид с разных грунтов суммировался. Далее суммарный годовой вынос биомассы был разделен на суммарную площадь грунтов, пригодных к выплоду хирономид, и тем самым получен средневзвешенный вылет за год с единицы площади акватории с учетом доли разных биотопов (грунтов) в общей площади водоема.

Годовой поток ПНЖК с единицы площади акватории (мг · м $^{-2}$ акватории) был рассчитан как произведение средневзвешенного вылета с единицы площади акватории и среднего содержания суммы ЭПК и ДГК в биомассе имаго (мг · $\Gamma^{-1}$ сырой массы). Последние величины были взяты из работы (Makhutova et al., 2017) отдельно для p. Glyptotendipes как наиболее часто встречающегося в пробах из ловушек таксона. Влажность биомассы имаго определяли в лаборатории высушиванием проб до постоянного веса при $75^{\circ} \mathrm{C}$.

\section{Результаты}

В 2017 г. с помощью картирования донных отложений были уточнены границы участков, занятые донными грунтами разных типов (рис. 1). Общая площадь акватории озера, пригодная к выплоду хирономид,

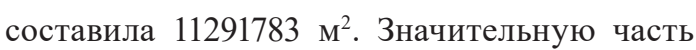

этой площади (64%) занимали заиленные грунты - 7266865 м² (рис. 1). Площади участков с песчаными, каменистыми и дернистыми грунтами были равны 1476969, 1691378 и 857562 м $^{2}$ соответственно.

За весь период исследований 20162017 гг., в ловушках обнаружены представители 17 видов хирономид из 9 родов: Chironomus (C. setivalva (Shilova, 1957), C. pallidivittatus (Malloch, 1915) и др.), Cladopelma viridulum (Linnaeus, 1767), Cricotopus (C. sylvestris (Fabricius, 1794) и др.), Cryptochironomus psittacinus (Meigen, 1830), Glyptotendipes (G. salinus (Michailova, 1987) и др.), Polypedilum (P. bicrenatum Kieffer, 1921 и др.), Procladius ferrugineus (Kieffer, 1918), Prodiamesa olivacea (Meigen 1818), Tanytarsus verralli Goetghebuer, 1929. Основной вклад в суммарный вылет учитываемый с помощью ловушек, давали представители родов Glyptotendipes и Polypedilum (табл. 1). Виды р. Chironomus составили заметную часть вылета ( 20 \% биомассы) лишь на станции 1 с глубины 6 метров. Виды р. Glyptotendipes составляли более половины биомассы вылетающих имаго в среднем по акватории и на большинстве точек наблюдений. Исключением была станция 1, где и на мелководье, и на глубине Glyptotendipes, Polypedilum и прочие таксоны обеспечивали равноценную часть вылета хирономид ( 30 \% биомассы) (табл. 1). Максимальные значения суточного вылета имаго, усредненного по рядам наблюдений двух вегетационных сезонов, соответствовали мелководью станции 3 (дерн, илы) и станции 4 (камень) (табл. 1). Данные о вылете с глубины 9 метров на станции 3 приведены не были в связи с их недостаточностью: попадания имаго в ловушки были единичными.

Сезонная динамика вылета имаго хирономид на мелководье заметно варьировала между станциями с разными типами грун- 


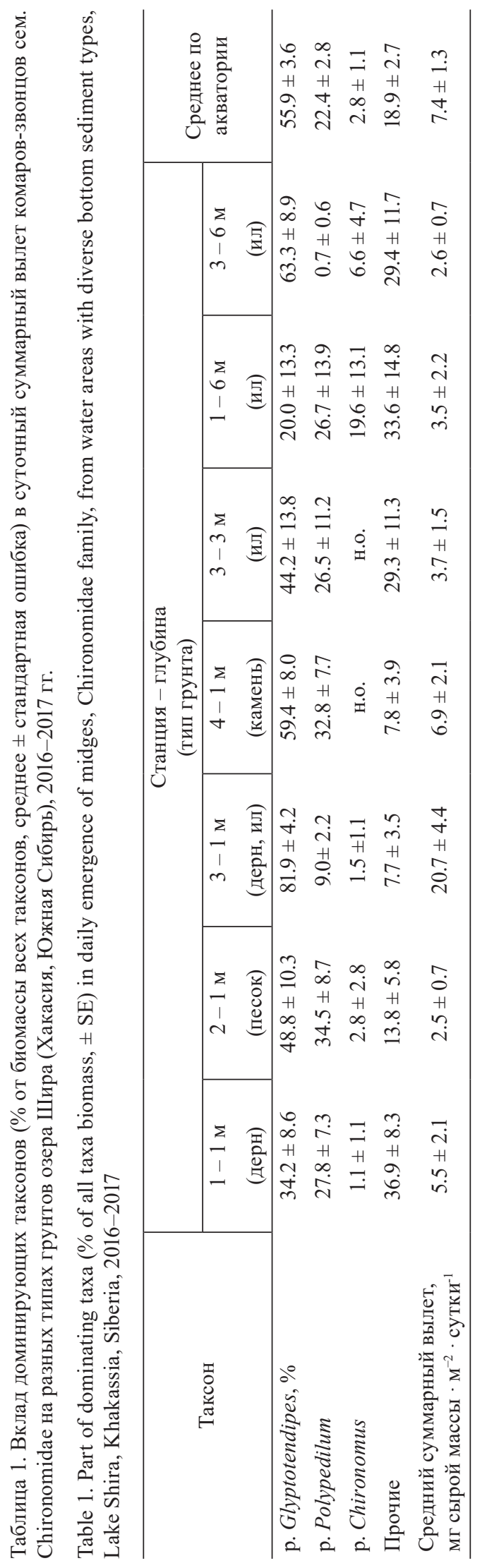


тов (рис. 3), но на всех участках наблюдался раннелетний локальный максимум вылета в интервале $550-850{ }^{\circ} \mathrm{C}$ суммарных положительных температур. Второй (среднелетний) пик вылета был характерен для всех станций, за исключением станции 4 с каме- нистым грунтом (рис. 3). Этот пик достигал максимального значения из всех наблюдений

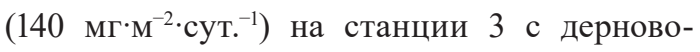
илистым грунтом. Основной вклад в оба сезонных пика принадлежал представителям р. Glyptotendipes. Однако следует отметить, что

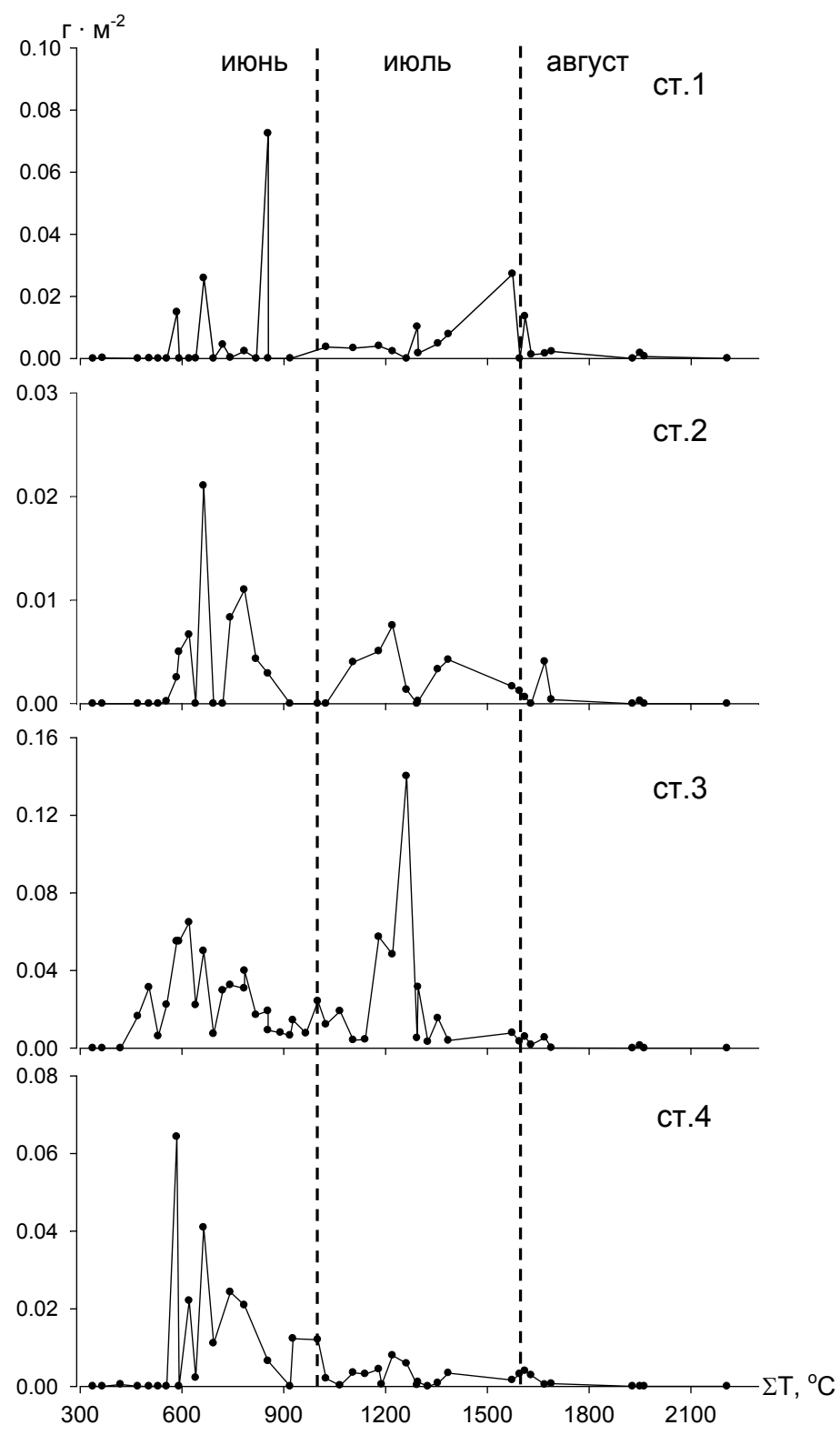

Рис. 3. Вылет имаго хирономид (г сырой массы ${ }^{-2}{ }^{-2}$ сут $^{-1}$ ) на станциях оз. Шира (только глубины 1 м), в зависимости от суммы накопленных положительных температур на сутки наблюдений, 2016-2017 гг.

Fig. 3. Emergence of chironomid adults ( $\mathrm{g}$ wet weight $\left.\cdot \mathrm{m}^{-2} \cdot \mathrm{day}^{-1}\right)$ from the stations in Lake Shira $(1 \mathrm{~m}$ depths only) versus cumulative sum of daily temperatures above $0{ }^{\circ} \mathrm{C}, 2016-2017$ 


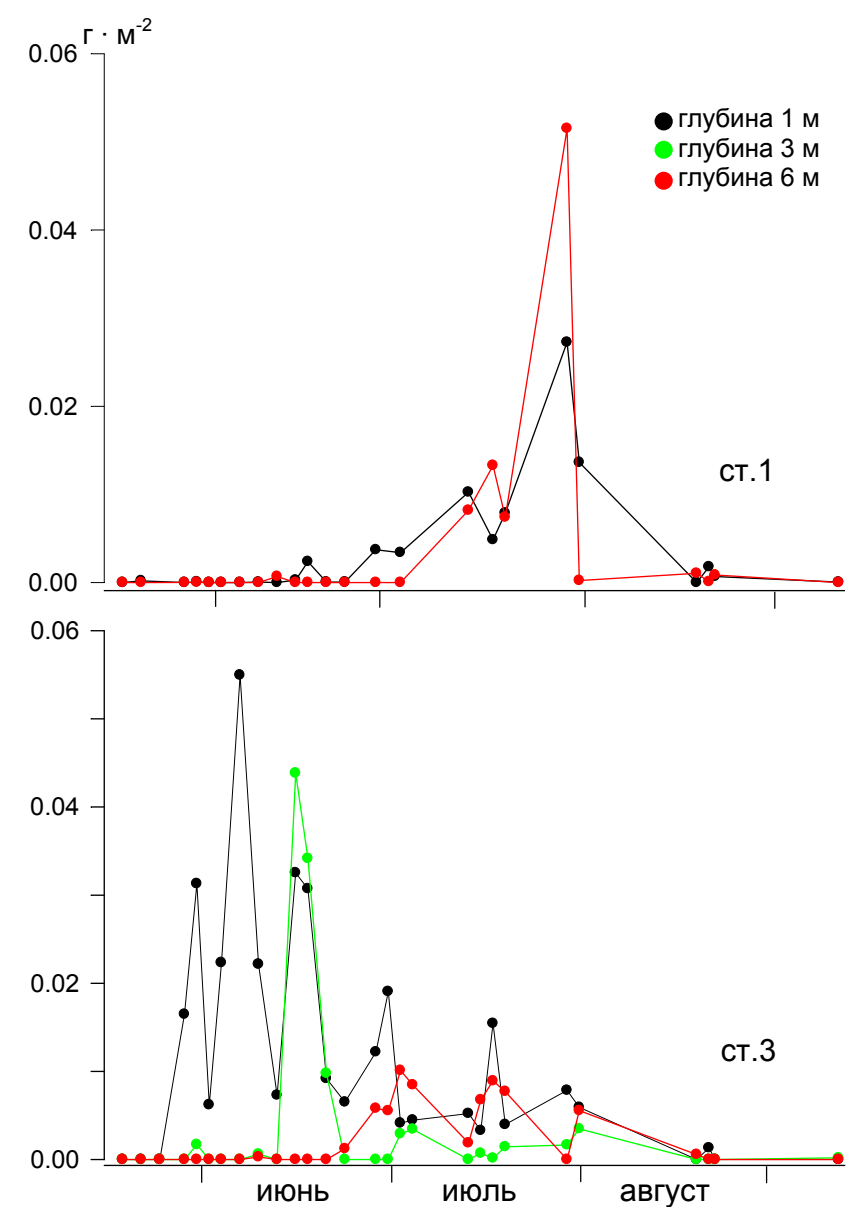

Рис. 4. Сезонная динамика суточного вылета имаго хирономид (г сырой массы $\left.{ }^{-2} \cdot{ }^{-1} \mathrm{c}^{-1}\right)$ на двух станциях оз. Шира на разных глубинах 1, 3 и 6 метров, май-сентябрь 2017 г.

Fig. 4. Seasonal dynamics of daily chironomid emergence ( $g$ wet weight $\cdot \mathrm{m}^{-2}$. day ${ }^{-1}$ ) from two stations in Lake Shira at 1, 3 and $6 \mathrm{~m}$ depths, May-September, 2017

второй пик вылета на станции 1 (рис. 3), соответствовавший интервалу суммы положительных температур $1500-1600^{\circ} \mathrm{C}$, определялся в основном вылетом видов р. Polypedilum.

На станциях с более пологим дном и подходящими ветровыми условиями (1 и 3) в 2017 г. была исследована сезонная динамика вылета хирономид на разных глубинах (рис. 4). На станции 1 (дерн, илистые грунты) сезонная динамика вылета с разных глубин была весьма сходной, при этом максимальная суточная величина вылета наблюдалась с поверхности над глубиной 6 метров в третьей декаде июля (рис. 4). На станции 3 вылет с разных глубин имел пики в разное время вегетационного сезона: на мелководье максимальные значения вылета наблюдались в конце мая и в раннелетний период; пик вылета с глубины 3 метра пришелся на середину июня; а с наибольших глубин (6 м) интенсивный вылет имел место лишь в конце июня и июля. Следует отметить, что летние максимумы с глубин 3 и 6 метров были обусловлены, прежде всего, вылетом комаров-звонцов р. Glyptotendipes и в меньшей или сопоставимой степени вылетом прочих видов (табл. 1).

Для разных участков озера были получены величины потоков биомассы за год 
Таблица 2. Расчеты потоков биомассы и суммы полиненасыщенных жирных кислот за счет вылета имаго хирономид из акватории оз. Шира, 2016-2017 гг.

Table 2. Estimated flows of biomass and sum of the polyunsaturated fatty acids per water area unit attributed to chironomid emergence from Lake Shira, 2016-2017

\begin{tabular}{|c|c|c|c|c|c|}
\hline Станция & $\begin{array}{c}\text { Годовой вылет, } \\
\text { г сырой массы · } \text { м }^{-2}\end{array}$ & $\begin{array}{c}\text { Тип } \\
\text { грунта }\end{array}$ & $\begin{array}{c}\text { Вынос биомассы } \\
\text { с грунта, } \\
\text { г сырой массы · год }{ }^{-1}\end{array}$ & $\begin{array}{c}\text { Средне- } \\
\text { взвешенный } \\
\text { вылет, } \\
\text { г сырой массы } \cdot \\
\cdot \text { м }^{-2} \cdot \text { год }^{-1}\end{array}$ & $\begin{array}{c}\text { Средне- } \\
\text { взвешенный } \\
\text { поток ПНЖК, } \\
\text { мг · } \text { м }^{-2} \cdot \text { год }^{-1}\end{array}$ \\
\hline $1-1 \mathrm{M}$ & 0.51 & \multirow{2}{*}{ Дерн } & \multirow{2}{*}{889294} & & \\
\hline $3-1 \mathrm{M}$ & 1.57 & & & & \\
\hline $2-1 \mathrm{M}$ & 0.21 & Песок & 310347 & & \\
\hline $4-1 \mathrm{M}$ & 0.48 & Камень & 815203 & & \\
\hline $3-1 \mathrm{M}$ & 1.57 & \multirow{4}{*}{ Ил } & \multirow{4}{*}{4904453} & & \\
\hline $1-6 \mathrm{M}$ & 0.42 & & & & \\
\hline $3-3 \mathrm{M}$ & 0.45 & & & & \\
\hline \multirow[t]{2}{*}{$3-6 \mathrm{M}$} & 0.27 & & & & \\
\hline & & Итого & 6919298 & 0.61 & 1.78 \\
\hline
\end{tabular}

(табл. 2), рассчитанные по модельному ряду суточного вылета относительно суммы накопленных положительных температур за сезон. Минимальное значение годового вылета хирономид, а также минимальный вынос биомассы с соответствующей площади наблюдались для участка распространения песчаного грунта (табл. 2). Максимальная величина годового вылета была характерна для дернистого грунта литорали, занимавшего весьма малую долю площади. На наиболее распространенных в озере илистых и каменистых грунтах наблюдались промежуточные значения годового вылета (табл. 2). Средняя величина годового вылета по акватории, рассчитанная с учетом количественного вклада разных типов грунтов в общую площадь водоема, составила 0.61 г сырой массы $\cdot \mathrm{M}^{-2}$, a c учетом измеренной влажности особей доминирующего вида хирономид - $71.5 \%$, около 0.2 г сухой массы $\cdot \mathrm{M}^{-2}$. В табл. 2 также приведена рассчитанная величина потока ПНЖК, выносимого с вылетом хирономид с единицы площади оз. Шира.

\section{Обсуждение}

Для сравнения полученной годовой величины найденные литературные данные о вылете хирономид были представлены с учетом принадлежности водоемов и водотоков к различным биомам (табл. 3), классификация и принятые границы которых приведены в работе (Olson et al., 2001). Следует отметить, что в большинстве литературных источников данные о количественном вылете амфибионтных насекомых с единицы площади акватории приводятся в единицах сухой массы.

Очевидно, что суммарный годовой вылет амфибионтных насекомых определяется как средней величиной интенсивности суточного вылета, так и длительностью вегетационного сезона. Так, в регионах с более теплым климатом, как правило, происходит несколько пиков вылета амфибионтных насекомых за вегетационный сезон (Rundio, Lindley, 2012). Климат региона, где расположено исследованное озеро, отличается засушливостью, но вместе с тем характеризуется и выраженной континентальностью, что определяет 
Таблица 3. Вынос биомассы хирономид (г сухой массы $\cdot \mathrm{M}^{-2} \cdot$ год $\left.{ }^{-1}\right)$ из водных экосистем, расположенных в различных климатических ландшафтах. Курсивом выделены данные для соленых экосистем

Table 3. Export of chironomid biomass ( $\mathrm{g}$ dry weight $\cdot \mathrm{m}^{-2} \cdot$ year ${ }^{-1}$ ) from aquatic ecosystems located in various biomes. Data for saline ecosystems are given in italics

\begin{tabular}{|c|c|c|}
\hline Водоем/Водоток & Годовой вынос & Литературный источник \\
\hline \multicolumn{3}{|c|}{ Бореальные и таежные леса } \\
\hline болото & 1.1 & Paasivirta et al., 1988 \\
\hline озеро & 1.9 & Dreyer et al., 2015 \\
\hline \multicolumn{3}{|c|}{ Хвойные леса умеренного климата } \\
\hline озеро & $0.2^{\mathrm{a}}$ & Sherk, Rau, 1992 \\
\hline озеро & 0.1 & Borisova et al., 2016 \\
\hline ветланд & $0.3^{6}$ & Lundstrom et al., 2010 \\
\hline \multicolumn{3}{|c|}{ Широколиственные и смешанные леса умеренного климата } \\
\hline озеро & 1.9 & Jackson, Fisher, 1986 \\
\hline ветланд & $1.1^{\sigma}$ & Leeper, Taylor, 1998 \\
\hline ветланд & 1.5 & Stagliano et al., 1998 \\
\hline ручей & 10.4 & Rolauffs et al., 2001 \\
\hline соленый марш & $0.2^{6}$ & MacKenzie, 2005 \\
\hline река & $1.2^{\mathrm{B}}$ & Paetzold et al., 2005 \\
\hline ручей & $3.7^{\mathrm{r}}$ & Johnson et al., 2013 \\
\hline пойменное озеро & 0.2 & Демина и др., 2013 \\
\hline \multicolumn{3}{|c|}{ Степи и прерии умеренного климата } \\
\hline ветланд & 1.2 & Whiles, Goldowitz, 2001 \\
\hline соленые реки & $2.7^{\text {д }}$ & Zinchenko et al., 2014 \\
\hline соленое озеро & 0.2 & наши данные \\
\hline \multicolumn{3}{|c|}{ Леса и кустарники Средиземноморья } \\
\hline ручей & 6.6 & Rundio, Lindley, 2012 \\
\hline \multicolumn{3}{|c|}{ Пустыни и ксерофитные кустарники } \\
\hline ручей & 23.1 & Jackson, Fisher, 1986 \\
\hline
\end{tabular}

\footnotetext{
${ }^{\text {a }}$ среднее значение рассчитано из табл. 2 источника.

${ }^{6}$ пересчитано с учетом сухой массы особи 150 мкг (Stagliano et al., 1998).

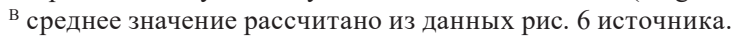

${ }^{\mathrm{r}}$ рассчитано из данных о вторичной продукции с учетом авторского соотношения вылет/продукция.

д приведены данные за один летний месяц с максимальным вылетом хирономид.
}

неустойчивость погоды внутри сезонов и от года к году, а также относительно небольшую продолжительность вегетационного сезона (Природный комплекс.., 2011). Несмотря на эти климатические особенности, на оз. Шира на большинстве типов грунтов отмечено два сезонных пика вылета в отличие от единичных пиков вылета, характерных, например, для горного озера, также расположенного в Сибирском регионе (Borisova et al., 2016).

Годовой вылет имаго хирономид из исследованного степного озера, составивший около 0.2 г сухой массы·м ${ }^{-2}$, был сопоставим с величинами, полученными для некоторых водных экосистем, расположенных в биомах хвойных и смешанных лесов умеренного кли- 
мата (табл. 3), например, ветландов Швеции, соленых маршей северо-востока США, пойменных озер Поволжья. Однако величины годового вылета хирономид, измеренные во многих водных системах умеренного и холодного климата, превышали величину вылета, полученную в нашей работе, на 1-2 порядка. Так, высокие уровни вылета наблюдали на озере Миватн, расположенном в геотермальном районе Исландии (Dreyer et al., 2015), болотах Финляндии (Paasivirta et al., 1988), ветландах юго-востока США (Leeper, Taylor, 1998), pyчьях и прудах Германии (Rolauffs et al., 2001). В свою очередь, диапазон значений вылета из водных объектов более «теплых» биомов степей и прерий, кустарников Средиземноморья, а также пустынь, был в несколько (5-33) раз больше полученного нами среднего значения для изученного степного озера (табл. 3). Таким образом, соленое оз. Шира отличалось достаточно низкой величиной годового вылета амфибионтных насекомых по сравнению с пресными и солеными водоемами и водотоками, расположенными в близких климатических зонах.

Согласно некоторым обобщенным данным считается, что вылет амфибионтных насекомых составляет около $24 \%$ от годовой вторичной продукции бентосных личинок (Huryn, Wallace, 2000). Мы сравнили таксономический состав и количественные характеристики вылета с известными характеристиками бентосного сообщества хирономид оз. Шира (Толомеев и др., 2018). На литорали станций 3 и 4 личинки G. salinus составляли 85-90 \% биомассы бентоса, а на станциях 1 и 2 доля этого вида была несколько меньше (41-45 \%) за счет выраженного доминирования P. bicrenatum (48-58 \% биомассы). Полученные нами данные о вкладе разных родов в общий вылет комаров-звонцов с мелководья (табл. 1) полностью согласуются с указан- ным таксономическим составом бентосных личинок. Однако отличительной особенностью бентоса озера являлись значительные различия в составе и биомассе доминантов литорали и профундали. На глубоководной части станций водоема доминировали личинки рода Chironomus (70-94 \%) и имели весьма высокие значения вторичной продукции, около 1.2 г сырой массы $\cdot \mathrm{M}^{-2} \cdot$ сут $^{-1}$ (Толомеев и др., 2018). Очевидно, что применяемые нами ловушки плавающей конструкции не улавливали основной массы особей р. Chironomus, проходящих метаморфоз на глубинах 3-6 м, поскольку их доля от вылета на этих глубинах колебалась лишь в пределах 6-20\%, а суммарный измеренный суточный вылет был заметно ниже, чем на литорали (табл. 1). Известно, что применение плавающих или полупогруженных ловушек значительно недооценивает вылет некоторых таксонов амфибионтных насекомых, например, многих видов стрекоз (MacKenzie, Kaster, 2004), вследствие особенностей прохождения их метаморфоза и развитых летных способностей имаго (Bogan, Boersma, 2012). Так, виды рода Chironomus оказывались в числе первых таксонов амфибионтных насекомых, заселявших искусственные пруды, установленные в аридной местности юго-востока Испании (Velasco et al., 1993).

В этой связи мы сравнили вылет и вторичную продукцию только литоральной части озера. Продукция хирономид, населяющих литораль, составляла в среднем 0.6 г сырой массы $\cdot$ м $^{-2}$. сут ${ }^{-1}$ (Толомеев и др., 2018), а потенциальный суточный вылет с учетом коэффициента 24 \% (Huryn, Wallace, 2000) может быть оценен в 0.14 г сырой массы $\cdot \mathrm{M}^{-2}$. Последняя величина превышала суточные значения вылета, измеренного на литорали 4-х станций с помощью ловушек, практически на порядок. Очевидно, что коэффициент, 
определенный для сообществ ручьев, состоящих в основном из поденок, ручейников и веснянок (Huryn, Wallace, 2000), может быть неприменим для хирономидного сообщества бентоса соленого водоема. С другой стороны, причиной таких значительных различий могло быть применение на литорали в 2016 и 2017 г. ловушек разных конструкций, вероятно, влияющих на сбор проб. Однако сравнение продукционных данных (Толомеев и др., 2018; С.П. Шулепина, персон. сообщение) и данных вылета разных типов ловушек, полученных в соответствующие вегетационные сезоны, показало, что уловистость ловушек двух типов не отличалась друг от друга и колебалась в пределах 1-3 \% от среднесуточной вторичной продукции, составляя в среднем $1.8 \%$.

Используя имеющиеся данные о вторичной продукции хирономид профундали и полученное соотношение вылета имаго и вторичной продукции личинок для данного озера, мы оценили потенциальный вылет за счет бентосного сообщества профундали, где доминировали представители р. Chironomus. Такой вылет составил в среднем около 1 г сырой массы в год с квадратного метра для всей площади акватории, пригодной к выплоду хирономид, а вынос биомассы из озера - дополнительно 11 тонн за вегетационный сезон. С учетом этой поправки суммарный годовой вылет имаго хирономид из соленого оз. Шира был около 0.5 г сухой массы $\cdot \mathrm{M}^{-2} \cdot$ год $^{-1}$, что также заметно меньше многих литературных значений (табл. 3).

Мы сравнили полученный поток ЭПК+ДГК с единицы площади акватории соленого озера (табл. 2) при вылете доминирующей группы насекомых - хирономид, с другими измеренными величинами потоков ПНЖК за счет вылета некоторых таксонов амфибионтных насекомых в конкретных ландшафтах. Так, значения годового потока ЭПК и ДГК (на единицу на площади акватории) из постоянных и временных пресных водоемов степи и лесостепи оказались значительно выше полученных нами данных: за счет вылета кровососущих комаров (сем. Culicidae, Diptera) - более чем вдвое (Gladyshev et al., 2011), а при вылете стрекоз (отр. Odonata) более чем в 7 раз (Popova et al., 2017). Экспорт ПНЖК из небольшого озера на юге Германии, обеспечиваемый вылетом хирономид ( 15 мг $\cdot \mathrm{M}^{-2} \cdot$ год $\left.^{-1}\right)$, был также в несколько раз больше соответствующей величины, измеренной в нашем исследовании (MartinCreuzburg et al., 2017).

Вместе с тем, оценка потока ПНЖК из оз. Шира, приведенная в табл. 2, не учитывает вклада видов Chironomus, обитающих на профундали. Известно, что виды этого рода отличаются весьма низким содержанием ПНЖК, 0.3 мг · Г'-1 (Makhutova et al., 2017). Следовательно, потенциальный экспорт ПНЖК с вылетом p. Chironomus, на основе указанных выше расчетных значений годового выноса биомассы и содержания ПНЖК в имаго этого таксона, можно оценить как 0.3 мг $\cdot \mathrm{M}^{-2}$. год ${ }^{-1}$. Эта поправка увеличит суммарный поток ПНЖК с квадратного метра акватории озера лишь на пятую часть. Таким образом, экспорт ПНЖК из оз. Шира является одной из самых низких измеренных величин, незначительно превышая лишь величину экспорта ПНЖК из горного сибирского озера (Borisova et al., 2016).

\section{Заключение}

Поток биомассы за счет вылета имаго хирономид с единицы площади степного соленого озера был сопоставим с рядом некоторых измерений для водных систем умеренного климата, но оказался одним из самых низких среди оценок для соответствующего ландшафта - степей и прерий. Вместе с тем, 
выполненные измерения существенно недооценили вылет видов хирономид, обитающих в глубоководной части озера. С использованием соотношения «продукция - потенциальный вылет имаго» и данных о вторичной продукции бентоса, расчетная величина суммарного потока биомассы может быть увеличена более чем вдвое. Таким образом, суммарный вынос биомассы хирономид с акватории озера, пригодной к выплоду, 11 км$^{2}$, составил около 18 тонн за год. Однако несмотря на эту до- полнительную оценку и высокое содержание ЭПК в вылетающих имаго р. Glyptotendipes, поток ПНЖК с единицы площади акватории был в несколько раз меньше величин экспорта при вылете хирономид, стрекоз и кровососущих комаров в подобных и иных ландшафтах. Наиболее вероятно, что очень малая величина экспорта ЭПК и ДГК обусловлена низкой продуктивностью изученного степного озера, а также относительно коротким сибирским вегетационным сезоном.

Работа была поддержана совместным грантом РФФИ - ККФПНиНТД 16-44240421р_а, грантом НШ-9249.2016.5 Совета по грантам Президента Российской федерации по государственной поддержке ведущих научных икол, проектом Сибирского отделения Российской академии наук № II.2П/VI.51-1, а также Государственным заданием в рамках программы фундаментальных исследований РФ, тема № 51.1.1.

\section{Список литературы}

Демина И.В., Ермохин М.В., Полуконова Н.В. (2013) Структура и динамика потоков вещества и энергии, формируемых при вылете имаго гетеротопных насекомых через границу «вода - воздух» пойменных озер р. Волга. Известия Саратовского университета. Новая серия. Серия Химия. Биология. Экология, 13(3): 85-93 [Demina I.V., Ermochin M.V., Polukonova N.V. (2013) Structure and dynamics of matter and energy flows by heterotopic insects imago emergence across the "water-air" surface of lakes in Volga river floodplain. Izvestiya of Saratov University. Series: Chemistry. Biology. Ecology [Izvestiya Saratovskogo universiteta. Seria Khimia, Biologia, Ecologia], 13(3): 85-93 (in Russian)]

Ландшафтная карта СССР (1980) Гудилин И.С. (ред.) Министерство геологии СССР. http:// www.etomesto.ru/map-atlas_landscape/? $\mathrm{x}=89.924782 \mathrm{\&}=54.628045$ [Landscape map of the USSR (1980) Gudilin I.S. (ed.) Ministry of Geology of the USSR (in Russian)]

Определитель насекомых Дальнего Востока России (1999) Двукрылые и блохи. Т. VI. Ч. 1. Владивосток, Дальнаука, 665 с. [Keys to the insects of the Russian Far East (1999) Diptera and Siphonaptera. Vol. VI. Part 1. Vladivostok, Dalnauka, 665 p. (in Russian)]

Природный комплекс и биоразнообразие участка «Озеро Шира» заповедника «Хакасский» (2011) Непомнящий В.В. (ред.) Абакан, Хакасское книжное издательство, 420 с. [Native community and biodiversity of "Lake Shira" area from the "Khakassian" natural reservation. Nepomnyashchii V.V. (ed.) Khakassian Book Press, 420 p. (in Russian)]

Толомеев А.П., Шулепина С.П., Махутова О.Н., Агеев А.В., Дроботов А.В., Сущик Н.Н. (2018) Характеристика таксономического состава и биомассы зообентоса соленого озера Шира: изменения, произошедшие за 65 лет. Журнал Сибирского федерального университета. Биология, 11(4): 367-383 [Tolomeev A.P., Shulepina S.P., Makhutova O.N., Ageev A.V., Drobotov A.V., Sushchik N.N. (2018) Taxonomic composition and biomass of zoobenthos in saline 
Lake Shira: shifts that happened in 65 years. Journal of Siberian Federal University. Biology, 11(4): 367-383 (in Russian)]

Arts M.T., Kohler C.C. (2009) Health and condition in fish: the influence of lipids on membrane competency and immune response. Lipids in aquatic ecosystems. Arts M.T., Brett M.T., Kainz M.J. (eds.) Springer, N.Y., p. 237-256

Ballinger A., Lake P.S. (2006) Energy and nutrient fluxes from rivers and streams into terrestrial food webs. Marine and Freshwater Research, 57(1): 15-28

Baxter C.V., Fausch K.D., Saunders W.C. (2005) Tangled webs: reciprocal flows of invertebrate prey link streams and riparian zones. Freshwater Biology, 50(2): 201-220

Borisova E.V., Makhutova O.N., Gladyshev M.I., Sushchik N.N. (2016) Fluxes of biomass and essential polyunsaturated fatty acids from water to land via chironomid emergence from a mountain lake. Contemporary Problems of Ecology, 9(4): 446-457

Bogan M.T., Boersma K.S. (2012) Aerial dispersal of aquatic invertebrates along and away from arid-land streams. Freshwater Science, 31(4): 1131-1144

Contreras-Lichtenberg R. (1999) Revision der westpaläarktischen Arten des Genus Glyptotendipes Kieffer, 1913 (Insecta: Diptera: Chironomidae). Teil 1: Subgenus Phytotendipes Goetghebuer, 1937. Annalen des Naturhistorischen Museums in Wien, 101B: 359-403

Cognetti G., Maltagliati F. (2000) Biodiversity and adaptive mechanisms in brackish water fauna. Marine Pollution Bulletin, 40(1): 7-14

Degermendzhy A.G., Zadereev E.S., Rogozin D.Yu., Prokopkin I.G., Barkhatov Y.V., Tolomeev A.P., Khromechek E.B., Janse J.H., Mooij W.M., Gulati R.D. (2010) Vertical stratification of physical, chemical and biological components in two saline lakes Shira and Shunet (South Siberia, Russia). Aquatic Ecology, 44(3): 619-932

Dreyer J., Townsend P.A., Hook III J.C., Hoekman D., Vander Zanden M.J., Gratton C. (2015) Quantifying aquatic insect deposition from lake to land. Ecology, 96(2): 499-509

Fureder L., Wallinger M., Burger R. (2005) Longitudinal and seasonal pattern of insect emergence in alpine streams. Aquatic Ecology, 39(1): 67-78

Gladyshev M.I., Arts M.T., Sushchik N.N. (2009) Preliminary estimates of the export of omega-3 highly unsaturated fatty acids (EPA+DHA) from aquatic to terrestrial ecosystems. Lipids in aquatic ecosystems. Arts M.T., Brett M.T., Kainz M.J. (eds.) Springer, N.Y., p. 179-210

Gladyshev M.I., Sushchik N.N., Makhutova O.N. (2013) Production of EPA and DHA in aquatic ecosystems and their transfer to the land. Prostaglandins and Other Lipid Mediators, 107: 117-126

Gladyshev M.I., Sushchik N.N., Yurchenko Yu.A., Belevich O.E., Kalacheva G.S. (2011) Differences in the fatty acid compositions of blood-sucking mosquito larvae and imagoes and the water-to-land export of essential acids. Doklady Biological Sciences, 441(1): 385-388

Gratton C., Vander Zanden M.J. (2009) Flux of aquatic insect productivity to land: comparison of lentic and lotic ecosystems. Ecology, 90(10): 2689-2699

Gray L.J. (1989) Emergence production and export of aquatic insects from a tallgrass prairie stream. Southwestern Naturalist, 34(3): 313-318

Herbst D.B. (2001) Gradients of salinity stress, environmental stability and water chemistry as a templet for defining habitat types and physiological strategies in inland salt waters. Hydrobiologia, 466(1-3): 209-219 
Hixson S.M., Sharma B., Kainz M.J., Wacker A., Arts M.T. (2015) Production, distribution, and abundance of long-chain omega-3 polyunsaturated fatty acids: a fundamental dichotomy between freshwater and terrestrial ecosystems. Environmental Reviews, 23(4): 414-424

Huryn A.D., Wallace J.B. (2000) Life history and production of stream insects. Annual Review of Entomology, 45: 83-110

Jackson J.K., Fisher S.G. (1986) Secondary production, emergence, and export of aquatic insects of a Sonoran desert stream. Ecology, 67(3): 629-638

Jeppesen E., Brucet S., Naselli-Flores L., Papastergiadou E., Stefanidis K., Noges T., Noges P., Attayde J.L., Zohary T., Coppens J., Bucak T., Menezes R.F., Freitas F.R.S., Kernan M., Sondergaard M., Beklioglu M. (2015) Ecological impacts of global warming and water abstraction on lakes and reservoirs due to changes in water level and related changes in salinity. Hydrobiologia, 750(1): 201-227

Johnson B.R., Fritz K.M., Price R. (2013) Estimating benthic secondary production from aquatic insect emergence in streams affected by mountaintop removal coal mining, West Virginia, USA. Fundamental and Applied Limnology, 182(3): 191-204

Lands W.E.M. (2009) Human life: caught in the food web. Lipids in aquatic ecosystems. Arts M.T., Brett M.T., Kainz M.J. (eds.) Springer, N.Y., p. 327-354

Langton P.H., Pinder L.C.V. (2007) Keys to the adult male Chironomidae of Britain and Ireland. Freshwater Biological Association Publishing, Ambleside, 239 p.

Leeper D.A., Taylor B.E. (1998) Insect emergence from a South Carolina (USA) temporary wetland pond, with emphasis on the Chironomidae (Diptera). Journal of the North American Benthological Society, 17(1): 54-72

Livingstone D.M., Lotter A.F. (1998) The relationship between air and water temperatures in lakes of the Swiss Plateau: a case study with palaeolimnological implications. Journal of Paleolimnology, 19(2): 181-198

Lundstrom J.O., Schafer M.L., Petersson E., Persson Vinnersten T.Z., Landin J., Brodin Y. (2010) Production of wetland Chironomidae (Diptera) and the effects of using Bacillus thuringiensis israelensis for mosquito control. Bulletin of Entomological Research, 100(1): $117-125$

MacKenzie R.A. (2005) Spatial and temporal patterns in insect emergence from a southern Maine salt marsh. American Midland Naturalist, 153(2): 257-269

MacKenzie R.A., Kaster J.L. (2004) Temporal and spatial patterns of insect emergence from a Lake Michigan coastal wetland. Wetlands, 24(3): 688-700

Makhutova O.N., Borisova E.V., Shulepina S.P., Kolmakova A.A., Sushchik N.N. (2017) Fatty acid composition and content in chironomid species at various life stages dominating in a saline Siberian lake. Contemporary Problems of Ecology, 10(3): 230-239

Marengo J.A., Jones R., Alves L.M., Valverde M.C. (2009) Future change of temperature and precipitation extremes in South America as derived from the PRECIS regional climate modeling system. International Journal of Climatology, 29(15): 2241-2255

Martin-Creuzburg D., Kowarik C., Straile D. (2017) Cross-ecosystem fluxes: Export of polyunsaturated fatty acids from aquatic to terrestrial ecosystems via emerging insects. Science of the Total Environment, 577: 174-182 
Millan A., Velasco J., Gutierrez-Canovas C., Arribas P., Picazo F., Sanchez-Fernandez D., Abellan P. (2011) Mediterranean saline streams in southeast Spain: What do we know? Journal of Arid Environments, 75(12): 1352-1359

Nakano S., Murakami M. (2001) Reciprocal subsidies: Dynamic interdependence between terrestrial and aquatic food webs. Proceedings of the National Academy of Sciences of the United States of America, 98(1): 166-170

Olson D.M., Dinerstein E., Wikramanayake E.D., Burgess N.D., Powell G.V.N., Underwood E.C., D’amico J.A., Itoua I., Strand H.E., Morrison J.C., Loucks C.J., Allnutt T.F., Ricketts T.H., Kura Y., Lamoreux J.F., Wettengel W.W., Hedao P., Kassem K.R. (2001) Terrestrial ecoregions of the world: a new map of life on Earth. BioScience, 51(11): 933-938

Paasivirta L., Lahti T., Peratie T. (1988) Emergence phenology and ecology of aquatic and semiterrestrial insects on a boreal raised bog in central Finland. Holarctic Ecology, 11(2): 96-105

Paetzold A., Schubert C.J., Tockner K. (2005) Aquatic terrestrial linkages along a braided-river: riparian arthropods feeding on aquatic insects. Ecosystems, 8(7): 748-759

Popova O.N., Haritonov A.Y., Sushchik N.N., Makhutova O.N., Kalachova G.S., Kolmakova A.A., Gladyshev M.I. (2017) Export of aquatic productivity, including highly unsaturated fatty acids, to terrestrial ecosystems via Odonata. Science of the Total Environment, 581-582: 40-48

Reimer J.P., Baerwald E.F., Barclay R.M.R. (2010) Diet of hoary (Lasiurus cinereus) and silverhaired (Lasionycteris noctivagans) bats while migrating through Southwestern Alberta in late summer and autumn. American Midland Naturalist, 164(2): 230-237

Richardson J.S., Zhang Y., Marczak L.B. (2010) Resource subsidies across the land-freshwater interface and responses in recipient communities. River Research and Applications, 26(1): 55-66

Rogozin D., Zadereev E., Prokopkin I., Tolomeev A., Barkhatov Y., Khromechek E., Degermendzhi N., Drobotov A., Degermendzhi A. (2017) Comparative study of the stability of stratification and the food web structure in the meromictic lakes Shira and Shunet (South Siberia, Russia). Ecology of meromictic lakes. Gulati R.D., Zadereev E., Degermendzhi A. (eds.) Springer International Publishing, N.Y., p. 89-124

Rolauffs P., Hering D., Lohse S. (2001) Composition, invertebrate community and productivity of a beaver dam in comparison to other stream habitat types. Hydrobiologia, 459: 201-212

Rosenberg D.M., Wiens A.P., Bilyj B. (1980) Sampling emerging Chironomidae (Diptera) with submerged funnel traps in a new northern Canadian reservoir, Southern Indian Lake, Manitoba. Canadian Journal of Fisheries and Aquatic Sciences, 37(6): 927-936

Rundio D.E., Lindley S.T. (2012) Reciprocal fluxes of stream and riparian invertebrates in a coastal California basin with Mediterranean climate. Ecological Research, 27(3): 539-550

Sabo J.L., Power M.E. (2002) River-watershed exchange: effects of riverine subsidies on riparian lizards and their terrestrial prey. Ecology, 83(7): 1860-1869

Schindler D.E., Smits A.P. (2017) Subsidies of aquatic resources in terrestrial ecosystems. Ecosystems, 20(1): 78-93

Sherk T., Rau G. (1992) Emergence of Chironomidae from Findley Lake and two ponds in the Cascade Mountains, U.S.A. Netherlands Journal of Aquatic Ecology, 26(2-4): 321-330

Stagliano D.M., Benke A.C., Anderson D.H. (1998) Emergence of aquatic insects from 2 habitats in a small wetland of the southeastern USA: temporal patterns of numbers and biomass. Journal of the North American Benthological Society, 17(1): 37-53 
Starry O., Wanzenböck J., Danielopol D.L. (1998) Tendency of the amphipod Gammarus roeseli Gervais to colonize coarse sediment habitats under fish predation pressure. International Review of Hydrobiology, 83(5-6): 371-380

Stenroth K., Polvi L.E., Faltstrom E., Jonsson M. (2015) Land-use effects on terrestrial consumers through changed size structure of aquatic insects. Freshwater Biology, 60(1): 136-149

Valero-Garces B.L., Navas A., Machin J., Stevenson T., Davis B. (2000) Responses of a saline lake ecosystem in a semiarid region to irrigation and climate variability: the history of Salada Chiprana, Central Ebro Basin, Spain. Ambio, 29(6): 344-350

Velasco J., Millan A., Ramirez-Diaz L. (1993) Colonización y sucesión de nuevos medios acuáticos II. Variación temporal de la composición y estructura de las comunidades de insectos. Limnetica, 9(1): 87-98

Whiles M.R., Goldowitz B.S. (2001) Hydrologic influences on insect emergence production from central Platte river wetlands. Ecological Applications, 11(6): 1829-1842

Williams W.D. (1998) The management of inland saline waters. Guidelines of Lake Management. Vol. 6. ILEC/UNEP, Kusatsu, 108 p.

Zinchenko T.D., Gladyshev M.I., Makhutova O.N., Sushchik N.N., Kalachova G.S., Golovatyuk L.V. (2014) Saline rivers provide arid landscapes with a considerable amount of biochemically valuable production of chironomid (Diptera) larvae. Hydrobiologia, 722(1): 115-128 